\title{
COVID-19's Impact on on ECE Communities Served by Minority Serving Institutions
}

\section{Dr. Kenneth A. Connor, Rensselaer Polytechnic Institute}

Kenneth Connor is an emeritus professor in the Department of Electrical, Computer, and Systems Engineering (ECSE) at Rensselaer Polytechnic Institute (RPI) where he taught courses on electromagnetics, electronics and instrumentation, plasma physics, electric power, and general engineering. His research involves plasma physics, electromagnetics, photonics, biomedical sensors, engineering education, diversity in the engineering workforce, and technology enhanced learning. He learned problem solving from his father (who ran a gray iron foundry), his mother (a nurse) and grandparents (dairy farmers). He has had the great good fortune to always work with amazing people, most recently the members and leadership of the Inclusive Engineering Consortium (IEC) from HBCU and HSI ECE programs and the faculty, staff and students of the Lighting Enabled Systems and Applications (LESA) ERC, where he was Education Director until his retirement in 2018. He was RPI ECSE Department Head from 2001 to 2008 and served on the board of the ECE Department Heads Association (ECEDHA) from 2003 to 2008. He is a Life Fellow of the IEEE.

\section{Dr. Kathy Ann Gullie, Gullie Consultant Services LLC}

Gullie Consultants Services LLC, Owner, Dr. Kathy A. Gullie Ph.D. Dr. Kathy Gullie and her associates at Gullie Consultant Services LLC have been in education, assessment, program development and evaluation in New York State for over 30 years. A former New York State teacher for 36 years, Dr. Gullie is committed to the improvement of education for students in all areas and education levels. Collectively, along with members of the team, Gullie Consultant Services LLC. has served as external evaluators for school districts, federal and state agencies, not-for-profit organizations, and institutions of higher education in New York State, as well as from around the country. Some of our past clients include: The National Science Foundation, the U.S. Department of Education, The New York State Department of Education, New York State VESID, State University of New York at Albany/SUNY, the State University of New York at Binghamton/SUNY, New York Institute of Technology (NYIT), Howard University, Morgan University and New York City Board of Education.

More specifically, Dr. Gullie has served the principal investigator/evaluator on several educational grants including: an NSF engineering grant supporting Historically Black University and Colleges through Howard University, the Syracuse City School District Title II B Mathematics and Science Partnership grants, Building Learning Communities to Improve Student Achievement: Albany City School District, Educational Leadership Program Enhancement Project at Syracuse University and the University at Albany through the Teacher Leadership Quality Program. She holds an advance degree in Educational Theory and Practice from the University of New York/SUNY Albany, with experience in teaching educational methods at the master's level as well as an introduction to education courses designed to develop new interest in teaching careers. She has worked as an elementary classroom teacher developing specific curricula for gifted and talented students as well as inclusion classrooms in a school district eligible for rural and low-income programs. Dr. Gullie's experience and past projects qualify her for the position of evaluator to examine the impact of the Alliance: Pathways to Success in Engineering (PASE). Her experience and qualifications working with data from multiple educational projects and personal work with students give her an in-depth understanding of the developmental nature of students participating

\section{Dr. Barry J. Sullivan, Inclusive Engineering Consortium}

Barry J. Sullivan is Director of Program Development for the Inclusive Engineering Consortium. His 40year career includes significant experience as a researcher, educator, and executive in industry, academia, and the non-profit sector. He has developed and delivered continuing education courses in communications technologies, and he guided the technology strategy for a start-up company delivering packet voice services. He was a full-time member of the faculty of the Department of Electrical Engineering and Computer Science at Northwestern University for more than six years, and has taught there as an adjunct 
faculty member. He also worked as a member of technical staff at Bell Laboratories. He received the B.S.E.E. and M.S. degrees from Marquette University, and the Ph.D. degree from Princeton University, all in electrical engineering.

Dr. Sullivan has served as an associate editor of the IEEE Transactions on Signal Processing, publications chair of the International Conference on Acoustics, Speech, and Signal Processing, and local arrangements chair for the Digital Signal Processing Workshop. He was also editor of THE BRIDGE, the magazine of Eta Kappa $\mathrm{Nu}$. He has published over forty papers on topics in signal reconstruction and image processing.

\section{Megan Bekolay \\ Dr. Dena T. Spaulding}

Dr. Spaulding is a program evaluator serving as an external evaluator on this NSF project.

\section{Dr. Mandoye Ndoye, Tuskegee University}

Mandoye Ndoye received the B.S.E.E. degree from the Rensselear Polytechnic Institute, Troy, NY, in 2002, the MS degree in Mathematics and the Ph.D. degree in electrical and computer engineering from Purdue University, West Lafayette, IN, in 2010. After completing his Ph.D. studies, he joined the Center of Applied Scientific Computing, Lawrence Livermore National Laboratory, as a Research Staff Member. From 2012 to 2014, he was a Research Associate at Howard University. Since 2014, he has been with the Department of Electrical Engineering, Tuskegee University, Tuskegee, AL where he is an Associate Professor. His research interests center on signal/image processing, sensor data analytics, intelligent infrastructure systems and power systems optimization.

\section{Dr. Otsebele E. Nare, Hampton University}

Otsebele Nare is an Associate Professor in the Electrical and Computer Engineering Department at Hampton University, VA. He received his electrical engineering doctorate from Morgan State University, Baltimore, MD, in 2005. His research interests include Multiobjective System Level Synthesis Techniques and K-16 Integrative STEM education.

\section{Dr. Abdelnasser A. Eldek, Jackson State University}

Dr. Abdelnasser A. Eldek obtained his Ph.D. in Electrical Engineering in 2004 from the University of Mississippi. Currently, he is Professor and Coordinator of Electrical and Computer Engineering at Jackson State University. His main research areas include Applied Electromagnetics, Antennas, Phased Arrays, RF/Microwave Circuits, Metamaterial, and Numerical Methods. 


\title{
Impact of the COVID-19 Pandemic on Electrical and Computer Engineering Programs at Minority Serving Institutions
}

\begin{abstract}
This study examines an organization that was designed to foster collaboration among Electrical and Computer Engineering (ECE) programs at nearly 20 Minority Serving Institutions (MSIs). Its member schools are among the top producers of African American and Hispanic engineers in the country. It has been working to build an organization that can enable the participating faculty, students and staff to engage fully in the national education and research enterprise; however, the COVID-19 Pandemic has put everyone at its partner institutions under unprecedented stress as campus operations moved online. It was essential that the experiences of the minority communities served be captured, especially during the critical spring 2020 semester when the move to distance delivery of classes was necessary. Lessons were learned and applied in the summer (in both courses offered and a large REU/RET program) and fall as universities worked to improve the learning experiences of their students. In addition to enhancing distance education efforts, nearly every tool and idea applied is a potential candidate for the infrastructure, programs and processes that can make it possible for the organization to realize its vision of enabling its partners to act in concert as a virtual super department.
\end{abstract}

\section{Introduction}

The great distance learning experiment is sweeping the nation's colleges and universities and wreaking havoc with their ability to deliver a high-quality learning experience for their students $[1,2,3]$. The MSIs who make up the organization are uniquely positioned to rapidly capture the experiences of minority engineering students and their instructors using the tools and approaches from their previous educational project.

ECE has historically been one of the largest programs in engineering so it is a reasonable choice to be broadly representative and provide a model for other disciplines. Based on discussions with MSI engineering deans, the level of collaboration achieved in the organization is unprecedented. In addition, the existence of a solidly functioning network of collaborators from many MSIs significantly increases the potential for success.

\section{Purpose}

The overall purpose of this RAPID project was to investigate and capture the experiences of ECE partner faculty and their students during the COVID-19 pandemic [1]. In addition, the primary emphasis of this specific investigation was to examine the changes occurring in engineering education during the spring of 2020, through Summer 2020 into Fall 2020, as courses moved and were adapted to being taught virtually. Spring 2020 data was used to document how faculty responded immediately to the crisis, whereas spring 2021 data is being used to verify the 
previous information and to validate themes and perspectives focused on identifying barriers, opportunities, sources of information, and collaborations, impacting the quality of the student learning experience and research activities done virtually and/or in hybrid and multiple platforms. As faculty respond to changes in their educational philosophy based on best practices for students learning, questions need to be raised as to what, if any, methodologies will be continued after universities return to on campus learning $[1,2,3]$.

The educational research that was pursued previously focused on documenting and understanding the impact of a personal instrumentation-based pedagogy and its enabling technology as a treatment to improve student learning and retention [4,5,6,7]. In the present effort, a similar approach is followed. The treatment is now distance delivery and learning and enabling technology includes tools for online meetings, forums, homework and quizzes [2].

\section{Research Questions}

Key research questions being addressed include: What were the challenges and improvements faculty observe in student interactions and outcomes through the online format? What do we need to know ahead of time to change an engineering course into an online format for students? What do online courses need to look like to meet the needs of students? What infrastructure is necessary to create and maintain a successful online course? What is the impact of an online centered course on student outcomes?

\section{Methods}

\section{Sample}

Data was gathered from faculty, undergraduates and graduate students at four distinct points in time during the pandemic: spring 2020, summer 2020, fall 2020 and spring 2021. This was considered "snapshot" data" from the stakeholders and not "matched" across time or treated as longitudinal data in a traditional sense. The purpose of collecting data in this manner was to find out how stakeholders were adapting and adopting to online instruction and what aspects they had improved upon for teaching and learning, as well as what were new barriers that had come about as this dilemma continued to extend itself across the academic year. Presented in Table 1 is an overview of the number of faculty and students in the project and the return rate for survey information from these groups. 


\section{Table 1}

\section{Overview of Sample Across Time}

\begin{tabular}{llll}
\hline Term & & $\begin{array}{l}\text { Total Surveys } \\
\text { Received }\end{array}$ & $\begin{array}{l}\text { Total Surveys } \\
\text { Completed }\end{array}$ \\
Spring 2020 & Post Faculty & 36 & 33 \\
& Post Student & 52 & 29 \\
Summer & Pre REU and RET & 26 & 26 \\
2020 & participants & & \\
& Post REU/RET & 13 & 10 \\
& participants & & 6 \\
& Post Faculty & 7 & 6 \\
& Post Graduate Mentors & 10 & 30 \\
& Post Students & 30 & 30 \\
Fall 2020 & Post Student & 47 & 15 \\
& Post Faculty & 15 & 32 \\
Spring 2021 & Pre Student & 32 & 23 \\
& Pre Faculty & 23 & \\
\hline
\end{tabular}

\section{Program/Structure of the Organization}

The organization for this project is a novel collaboration among ECE programs at nearly 20 Minority Serving Institutions (MSIs) [8]. Its member schools are among the top producers of African American and Hispanic engineers. It has been working to build an organization that can enable the participating faculty, students and staff to engage fully in the national education and research enterprise. The COVID-19 Pandemic has put everyone at its partner institutions under unprecedented stress as campus operations moved online [1,2]. It was essential that the experiences of the minority communities served be captured, especially during the critical spring 2020 semester when the move to distance delivery of classes was necessary [1]. Lessons were learned and applied in the summer (in both courses offered and a large REU/RET program) and fall as universities worked to improve the learning experiences of their students. In addition to enhancing distance education efforts, nearly every tool and idea applied is a potential candidate for the infrastructure, programs and processes that can make it possible for the organization to realize its vision of enabling its partners to act in concert as a virtual super department. 


\section{Instrumentation}

For the purpose of this investigation several surveys were designed and developed. These surveys focused on "capturing" the experiences of partner faculty and their students as they worked through the COVID-19 pandemic. These surveys were administered online.

Faculty were asked to share their perspectives on the integration of the new rules into their course platforms and plans. Included in this paper is an outline of their responses organized by theme, to questions about how they worked through the pandemic situation.

For students, questions focused on identifying barriers to learning, opportunities for learning, sources of information, and collaborations, overall impact of learning virtually and the quality of the student learning experience, and research activities done at a distance. To gather this information from REU/RET graduate mentors and undergraduate students, surveys were developed and administered electronically. Items for the surveys were both Likert type items and open ended to gather in depth information about how they moved from face to face to online/virtual classrooms and how they addressed challenges along the way. The data included an analysis of student reflections comparing perceptions from the spring 2020 semester of the COVID-19 pandemic through to the present spring 2021 semester. Information focused on student perceptions during that time period. Qualitative and quantitative data were gathered and analyzed using themepattern analysis for both faculty and students.

\section{Results}

Faculty

Overall instructors needed some preparation in order to develop appropriate methods and materials during transitioning from face-to-face classes to virtual platforms. Faculty described a number of modifications to the curriculum, mainly in methods of delivery. These methods included more video communications and Canvas/Blackboard type platforms.

\section{Modifications made to Curriculum.}

Modifications included recorded lectures, virtual office hours, Addition of SLACK for communication; ThinkerCad and Multisim were the students' preferred tools for use in virtual courses. The objectives were not modified, only the intensity of programming in the online software was increased. The biggest change to the curriculum was to move the physical project to a fully simulated one. Faculty maintained structured online teaching using Blackboard Ultra during the regular class times and sometimes Zoom for tutoring. During live lab sessions, breakout rooms for utilized to address student specific questions through utilizing the screen 
sharing options in Blackboard Collaborate Ultra; Used video-conferencing to instruct students (either as synchronous lectures or to instruct students on how to conduct lab assignments) Discussions: Online using Canvas, which were already part of course

Maintaining student interest and engagement; "Participation in live lectures dropped so I recorded them for students to have access to information”. Breakout rooms were utilized to address student specific questions through utilizing the In faculty reported that the content itself was not impacted by the sudden transition. Faculty employed a variety of assessment methods. These assessments included: online testing, virtual classroom projects, student status reports, as well as private conversations between faculty and individual students. In addition to faculty needing support during the transition, faculty also reported that students needed support from the universities as well. Faculty chose a number of methods to document students' knowledge while working virtually. These methods included, but were not limited to, online discussions, review questions, and in-depth problem- solving activities. However, there were some limitations in areas where particular content could only be examined through test and quiz grades.

\section{Modifications Made to Assessment Methods/Documenting Student Knowledge.}

Weekly assignments grade, online exams, classwork problems for the students to complete in class to allowing for checking for understanding; Exams are completed during scheduled times; students scan exams using smartphone Apps and submit it to instructors via email.

Instituted Projects Day. Faculty gauged content understanding through "review questions" derived from quizzes, student provided answers through chat room and online exams Posting and broadcasting of resolved Q\&A from students to the entire class made a positive impact in material understanding of students.

According to some constant questions during class online; In some cases instructors were unable to assess whether students had a good grasp on the subject other than looking at the grades in the quizzes and exams.

A deliberate use of problems to engage the students during the class period to determine which approach was more effective in communicating concepts to the students was used.

WhatsApp groups and online evaluations to monitor understanding of the issues and formative assessment tools such as ungraded polls and graded weekly quizzes have helped faculty track student learning during the quarter

Faculty did not indicate an overall change in philosophy of education; however, faculty did suggest that motivation is key to student success. Some also suggested areas where online platforms could help students learn but noted limitations for some students as it pertained to their 
living environment and online access. Overall, faculty indicated that the COVID-19 situation has helped them to reinvent themselves through course and content redesign, learning about and training in the use of virtual tools that are the tools of new generations and understanding the importance of the resiliency of students.

\section{Modifications Made to Courses}

Online formats were added: i.e. Blackboard, MATLAB, Video lecture; some virtual taped and other in person live, Hands-on experiments had to be modified to simulation experiments; transition to online using Blackboard Ultra. Some faculty shipped out ADALM2000 boards to students for the labs and modified the lab exercises to allow for completion individually and with reduced number of ICs. Hands-on experiments had to modified to simulation experiments but in some courses simulation was not possible and increased availability of office hours for assistance with completion of laboratory assignments. Some faculty recorded online lectures etc. to be share with students

Additionally, other methods included project teams met as a group and then instructor checks in to see where they are, while some faculty suggested that the main steps taken included finding the tools that were freely available to all the students.

\section{Faculty responses to the situation Preparation:}

Some faculty were not prepared at all and needed support; but a number of universities proved a quick or short training, while others had some experience with online platforms and were somewhat prepared, most had a about a week to training and adapting, Transition to virtual lessons and online lectures was at first an emotional barrier, practicing a few times eased that situation. The major training was also needed to complete involved giving remotely proctored examinations, and "A few workshops and training prior to online delivery mainly how to use Moodle but still many questions remain unanswered."

\section{Challenges in moving courses online}

Learning use of online tools for active learning; modify teaching materials substantially for a different pace and platform was a process that was extremely time consuming. Faculty said they needed to devise new labs with inverse approach. Some issues with monitoring or proctoring an online exam and administering fair exams in remote settings were realized. Communication between team members, or lack thereof, impacted team dynamics, and some had to sacrifice team-based learning in this situation as there was limited time to move everything online. Faculty indicated that maintaining student interest and engagement and the online courses need to be continually revised and improved to remain fresh and up to date. 


\section{Benefits faculty perceived for students}

Students working at their own pace, students were able to keep kits, and RET were able to implement some hands-on activities in their classrooms.

\section{Challenges for faculty student relationships/interactions}

Frequent meetings with the REUs and RETs during the week by Faculty and Mentors and met some challenges as there were some schedule conflicts. Faculty materials purchases for some were challenging. (i.e. vendors, payment methods and shipping time). Many indicated that it was difficult to determine if a student needed help as some student were reluctant to ask. Because of virtual experience rather than face to face, The REUs and RETs do not get a real feeling of what it means to be a graduate student and do some experimental work in a lab.

\section{Graduate Mentor perspectives Themes shared Benefits}

The addition of meetings and understanding so many people's opinions and ideas as well as overall knowledge gained in use of various technologies

\section{Challenges}

Challenges were limited to access to the materials and personal interactive environment (i.e. the environment developed in a lab through collaboration and cooperation). Additionally some specific concepts are just difficult to explain virtually,

\section{RET/REU Student Responses/ Themes Shared \\ Benefits}

Responses focused on working with teams virtually to conduct research. Flexibility with working time, friendships built, networking opportunities and mandatory meeting schedule ensured an opportunity to communicate were key.

\section{Challenges}

Working to solve problems without physical contact were sometimes harder to show one's work effectively and explain it. Issues focused on network connection issues, troubleshooting hardware or software issues as well as impromptu meetings aligned with everyone's time/schedule. There were also unintended distractions when working from home, being fully present can be an issue

\section{Faculty themes became evident Spring 2021}

Most felt somewhat prepared because of their experience during the last year and were prepared to make the instructional changes because of prior online teaching experience from Fall 2020 and partial Spring 2020, they indicated that they had a better understanding of the resources 
available and challenges that the students face during the course. Many indicated that training that they received from their institution helped transition to this new mode of instruction.

\section{Student: Pre- survey Reflections spring $2021(\mathrm{n}=\mathbf{2 5})$}

Students were asked: What, if any, possible positives can you see in the changes in instructional presentation? What negatives might you have realized?

Respondents indicated that there were a number of positives in changes in instructional presentation, for example some said: The institution really prepared for the online classes. Providing the tools and equipment to be more effective in classes, and they saw better technology usage and personal time management. Another suggested that they could now see the variation of programs that the they can use to study and will use it for the class and also that recording of classes allowed students to go over the class at their own pace

As for negative reactions, some students stated that instructional presentations were merely the same though, that it was a lot harder for us (students) trying to understand concepts through a computer rather than a classroom white board and for some students to learn information because they are tactile learners. Also, assessment platforms were not viewed as positive. One student commented "Instructors need to realize that the pandemic does not just affect them. It is hard enough to learn inside the classroom, and to have to learn virtually with little to no engagement makes me feel that they do not care about my education at the end of the day. It should be noted that eight (8) of 25 students saw no positives or negatives to report.

\section{Conclusion}

As instructors we all adapt to new learning situations on a regular basis. Instructors continually refine their pedagogy trying out "new" teaching practices, and students have to adapt and adapt to new ways of learning based on the new approaches placed before them. While faculty tend to do this more regularly in face to face settings, the move to try out new approaches to teaching and learning, particularly in fields such as engineering, have been slower to take hold in a virtual, distance learning environment.

The introduction of COVID-19, however, unexpectedly accelerated faculty to move courses traditionally taught face to face to online modalities within weeks, creating a unique social experiment. The purpose of this study was to try and understand how faculty navigated these uncharted waters, along with their needs, success stories and continued challenges to deliver effective pedagogy in the field of engineering. In addition, students, both undergraduate and graduate, were examined to gather their perceptions of the overall experience, and like faculty, document the benefits, the challenges, and their continued need for areas of support in this new world of online learning. Both faculty and students noted the benefits and the challenges that exist 
with online learning. While there are benefits of moving to online platforms for course instruction in engineering, providing labs settings that are effective for not only teaching necessary skills, as well as the over "experience" still remain a challenge. It is anticipated that as faculty and students return to face to face teaching that some components of their online experience will continue. Future studies should ascertain what specific components will be retained.

\section{References}

1. Fox, M. F. J., Werth, A., Hoehn, J. R. and Lewandowski, H. J.. (2022). Teaching labs during a pandemics: Lessons from Spring 2020 and an outlook for the future. JILA. University of Colorado, Boulder.

2. Astatke, Y., Scott, C. J., Connor, K. A., and Ladeji-Osias, J. O. (2012). Online Delivery of Electrical Engineering Laboratory Courses," ASEE Annual Conference and Exposition, San Antonio, June 2012

3. Ko, S and Rossen, S. (2017). Teaching online: A practical guide. New York: NY. Routledge.

4. Astatke, Y, Connor, K.A., Newman, D. L, Attia, J.O. \& Nare, O. E. (2016). Growing experimental centric learning: the role of setting and instructional use in building student outcomes" 2016 ASEE Annual Meeting, New Orleans, Paper ID\# 17030

5. Connor, K. A., Y. Astatke, C.J. Kim, C. J., A.A. Eldek, H.R. Majlesein, H. R., P. Andrei, J.O. Attia, \& K.A. Gullie, C.A. Graves, and A.R. Osareh, A. R. (2015). Simultaneous Implementation of Experimental Centric Pedagogy in 13 ECE Program" Paper presented at 2015 ASEE Annual Conference and Exposition, Seattle, Washington.

6. Connor, K, Newman, D., Gullie, K. , Astatke, Y., Chouikha, M. (20160. Experimental Centric Pedagogy in First-Year Engineering Courses", ASEE's 123rd Annual Conference \& Exposition • New Orleans, LA • June 26-29, 2016. Paper ID \#17052

7. Hasan Ozgur Kapici, Hakan Akcay \& Ton de Jong (2020). How do different laboratory environments influence students' attitudes toward science courses and laboratories?, Journal of Research on Technology in Education, DOI: 10.1080/15391523.2020.1750075 https://doi.org/10.1080/15391523.2020.1750075

8. National Science Board Science \& Engineering Indicators. (2020). Higher Education in Science and Engineering, NSB-2019-7, September 4, 2019. https://ncses.nsf.gov/pubs/nsb20197/ 